\title{
A physical model of energetic processes in a diesel marine generator set
}

The paper presents a physical model of energy related processes taking place in a diesel marine generator set. The development of a physical model was preceded by an analysis of the design structure of the investigated object and the flow of parameters among the functional modules of the model object. The above was completed by developing of functional and topological models. Only their analysis allowed the development of the proper physical model.

Keywords: physical model, modeling, diesel engine, diagnostics

\section{Introduction}

According to the requirements of the SOLAS convention [12], each vessel must be equipped with at least two sources of electrical energy. In most of the cases these are marine generator sets composed of a medium or high-speed combustion diesel engine and a synchronous generator. Majority of engines used to power the generators are designs of, as we call it, low diagnosability, which means there are no easily measurable parameters providing clear information on the engine technical condition. Such engines are operated according to hourly service life that assumes a renewal of subassemblies after a precisely determined period of operation. A much more advantageous strategy is the engine maintenance based on its technical condition, according to which the maintenance is carried out based on intermittent or continuous measurements of the diagnostic parameters. To this end, works are underway to develop non-invasive (without impact on the engine design structure) methods of assessment of the technical condition of low diagnosability piston engines. The physical model of a marine generator set presented in the paper is a preliminary stage in the development of the method of assessment of the engine condition based on the measurement of interphase voltages of the coupled generator. The starting point in the conducted investigations was the assumption that the engine condition has significant impact on the fluctuation of its speed, hence the rotor of the synchronous generator. Therefore, any change in the angular velocity (during the engine work cycle) results in a deformation of the curve of the interphase voltage.

The first stage of the investigations related to the processes occurring in the energy generating devices, in this case the engine-generator assembly, is the preparation of the research plan. It is most often presented as an algorithm containing all forecasted stages of the research [1, 4]. The adopted plan has been presented in Fig. 1.

The presented diagram of the research has been divided into two main stages. The first one includes the development of a mathematical model of the engine powering the generator and the second one, the development of the mathematical model of the engine- generator assembly.

Such an approach to the problem results from the complexity of the modeled processes and the fact that the model validation in the case of the investigated marine generator sets is practically impossible. This is due to the low diag- nosability of the engines under analysis (these engines are not fitted with indictor valves).

The stage of modeling of a marine engine is composed of the following elements: research object (referred to as real object), physical model, mathematical model and a computer program. The real object was the marine engine of high diagnosability (four stroke piston diesel engine fitted with indicator valves). A physical model was developed for this engine covering selected engine processes. The physical model constitutes a basis for the development of the mathematical model, whose equations are implemented in the computer program. The mathematical model is validated based on a comparative analysis of the obtained results of the model and empirical investigations. It was assumed that these investigations should be carried out for different states of technical worthiness (the same for the model and the real object) i.e. full and partial worthiness [5]. The performed comparative analysis of the results allows a modification of the model equations until assumed adequacy is reached. The obtainment of sufficient adequacy denotes completion of the first stage and initiation of the second one.

The second stage, i.e. the development of the mathematical model of the marine generator set consists in expanding the model from stage one by equations describing the operation of the synchronous generator. Similarly to the first stage, the equations of the mathematical model allow the extension of the computer program (developed following the first stage). The validation of the mathematical model is performed through a comparative analysis of the results obtained in the empirical research (active experiment) and the results of modeling for various conditions of worthiness of the generator engine. If the model adequacy is lower than the assumed one, the equations are modified until the desired adequacy is reached. All results (obtained in the model and the experimental research) for the marine generator set are stored in an 'engine condition-symptom' database, which should in the future allow an identification of the engine technical condition based on the generator interphase voltage measurements.

\section{Physical model of the energetic processes occurring in marine engines}

According to the definitions available in the subject literature $[7,8]$, a physical model is a concept of theoretical 


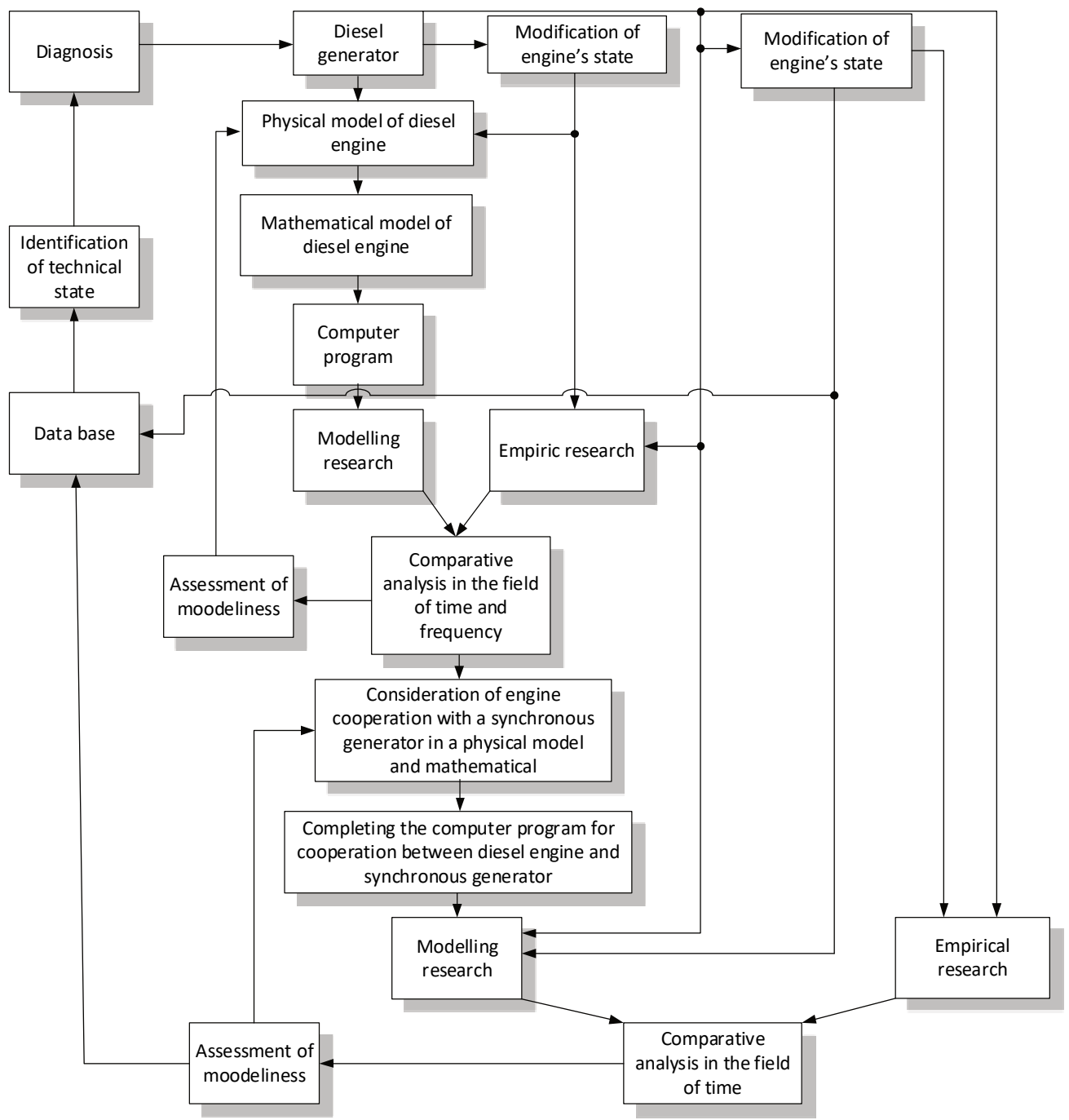

Fig. 1. RDE tests requirements in Europe [4, 5]

reproduction of phenomena and processes occurring in the modeled object (real object). It covers a set of assumptions defining a certain simplified representation of an object of the model analysis and contains all the relevant quantitative and qualitative relations.

According to the above definition, each physical model involves a simplification of reality. The extent of the simplifications depends on subjective and objective factors. The objective factors are the current state of knowledge, the possibility of identification of all the processes and phenomena occurring in the object and the ability to describe them with appropriate qualitative and quantitative relations. The subjective factors are the needs and the technical conditions of the realization of the model analysis of the investigated object. Therefore, majority of models has far reaching simplifications of reality, limited to processes and phenomena that are significant from the point of view of the researcher [7, 8].

The development of a physical model is always preceded by an analysis of the design and principle of operation of the research object. Particularly significant is the determination of the mutual relations among the components of the modeled object. Such an analysis can be carried out by developing a functional and a topological model. The functional model presents the flow of signals (parameters) among the components of the design structure of a marine engine. The topological model (presented in the form of a graph) presents mutual relations among individual parameters of the engine operation. Both models aim at incorporating significant (from the point of view of the researcher) features of an object while in the case of the less significant ones, simplifications or omissions are applied.

\subsection{Functional model}

The functional model presents the flow of signals (parameters) among the components of the structure of the modeled object.

The functional model of the engine-generator assembly presented in Fig. 2, has been developed for the investigations related to the influence of the technical condition of the engine on the curves of the generator interphase voltages during a work cycle. The assumed designation of the model has determined its detail level and the modeling range of individual components and processes. In the presented model the fundamental subassemblies have been included (functional modules) of high significance for the engine operation: 


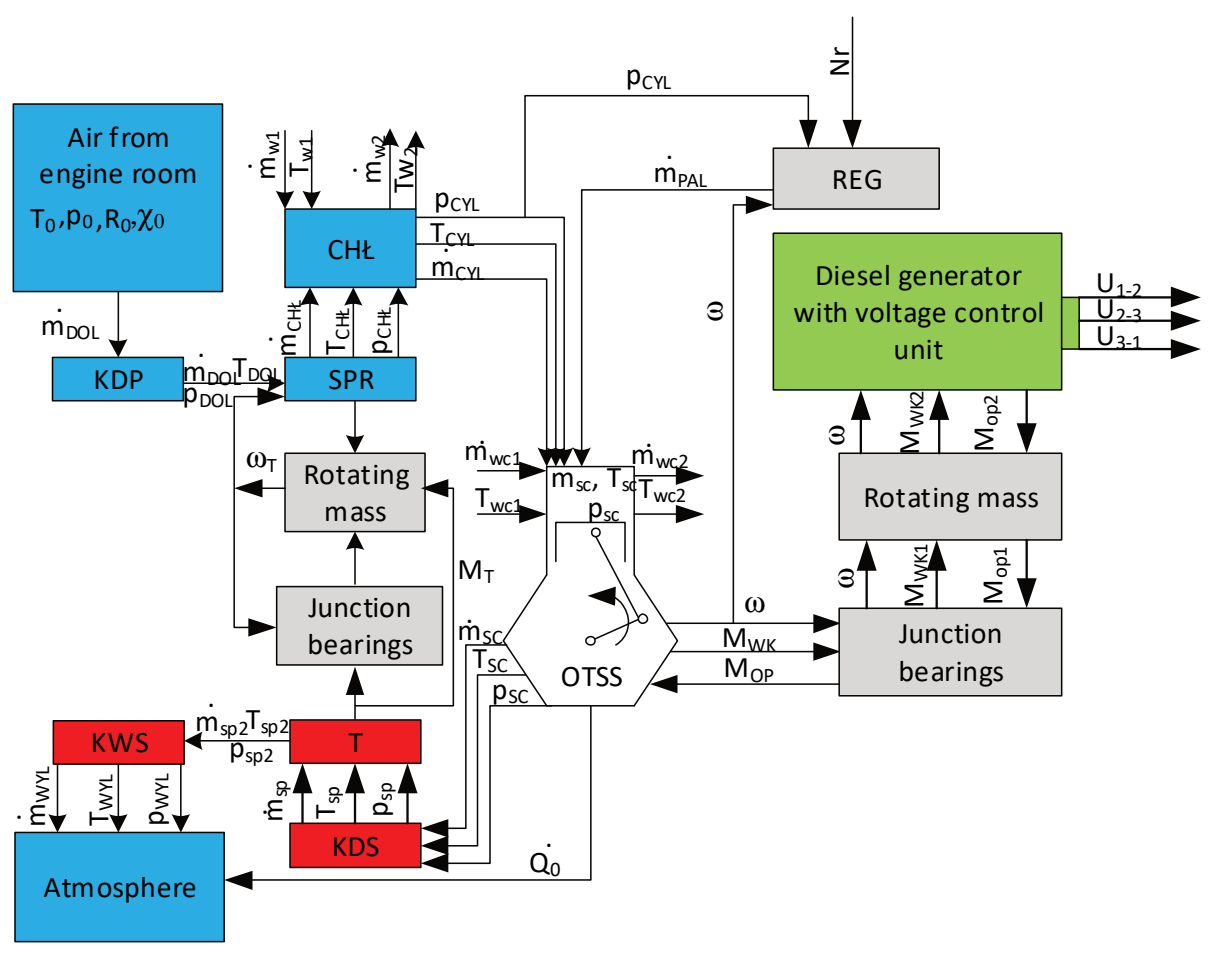

Fig. 2. Functional model of the engine-generator assembly

- air intake KDP,

- compressor S,

- intercooler CHE,

- cylinder sections OTSS,

- engine speed regulator REG

- generator with voltage regulator,

- turbine T,

- bearing nodes,

- rotating masses,

- exhaust gas inlet to the turbine KDS,

- exhaust gas outlet KWS.

Majority of the functional models (except voltage regulator, engine speed regulator, bearing nodes, rotating and reciprocating masses) can accumulate mass of the flowing medium and its energy. The rotating masses accumulate mechanical energy, thus playing the role of kinetic accumulators.

Additionally, each of the engine components can accumulate thermal energy generated during combustion of fuel inside the cylinders and that resulting from friction. Besides, in the functional model the 'flow' of individual physical parameters (signals) among the functional modules was presented. In the case of flow components, these are mass flows of the thermodynamic medium, its temperature, pressure, individual gas constant, specific heat, etc. In terms of the heat exchange between the thermodynamic medium, the components of the model design structure and the surroundings (cooling water, air and lubricating oil) these are heat flows or, in the case of cooling water and oil, these are mass and temperature flows at the inlet and outlet from the cooled component.

The model assumes a generator with a voltage regulator. They were modeled as components generating the moment of resistance. Additionally, rotating and reciprocating com- ponents of the crank-piston assembly were included in the model. Due to their mass and moment of inertia, they have a significant influence on the values of the fluctuation of the angular velocity of the generator rotor as a function of crankshaft angle. When developing the functional model, the authors also included components influencing the course of the engine processes (engine speed regulator and bearing nodes). Further in the research, the bearing nodes were omitted, as they introduced certain inertia effects to the engine processes. Their impact, however, (if operative) was miniscule. All engine processes are time dependent. The authors decided to take a quasi-static approach in the model, which means that all dynamic processes are treated as a sequence of consecutive steady states.

The input parameters for the functional model of a marine engine are the parameters of the ambient air such as: temperature $T_{0}$, pressure $\mathrm{p}_{0}$, individual gas constant $\mathrm{R}_{0}$ and humidity $\varphi_{0}$. Mass flow of air gets to the intake duct $\dot{\mathrm{m}}_{\mathrm{DOL}}$. Then, the medium of the parameters: mass flow $\dot{\mathrm{m}}_{\mathrm{DOL}}$, temperature $\mathrm{T}_{\mathrm{DOL}}$ and pressure $\mathrm{p}_{\mathrm{DOL}}$ flows to the compressor SPR, where it is compressed to reach the parameters: $\dot{\mathrm{m}}_{\mathrm{CH}}, \mathrm{p}_{\mathrm{CH}}$ and $\mathrm{T}_{\mathrm{CH}}$. The air parameters at the outlet from the compressor are the input parameters of the intercooler CHE. Inside the intercooler, a heat exchange takes place between the air and the cooling water. The parameters of the cooling water at the inlet to the intercooler are: mass flow $\dot{\mathrm{m}}_{\mathrm{w} 1}$ and temperature $\mathrm{T}_{\mathrm{w} 1}$. The cooling water at the outlet from the intercooler has the parameters $\dot{\mathrm{m}}_{\mathrm{w} 2}$ and $\mathrm{T}_{\mathrm{w} 2}$. The mass flows of water at the inlet and outlet from the intercooler are identical $\dot{\mathrm{m}}_{\mathrm{w} 1}=\dot{\mathrm{m}}_{\mathrm{w} 2}$. The air at the outlet from the intercooler (at the inlet to the cylinders) has the following parameters $\dot{\mathrm{m}}_{\mathrm{CYL}}, \mathrm{p}_{\mathrm{CYL}}$, and $\mathrm{T}_{\mathrm{CYL}}$. In the entire air supply system, the value of the individual gas constant is steady and equals $R_{0}$. A mass flow of fuel $\dot{m}_{\mathrm{PAL}}$ is 
fed to the cylinders. Its value depends on the engine speed regulator REG. The input parameters in the case of the modeled engine speed regulator are: air pressure at the outlet from the intercooler $\mathrm{p}_{\mathrm{CH}}$ and the angular velocity of the crankshaft $\omega$. The cylinder walls and the cylinder head are cooled with water. The parameters of the cooling water at the inlet to the cylinder area are mass flow $\dot{\mathrm{m}}_{\mathrm{wc} 1}$ and temperature $\mathrm{T}_{\mathrm{wc} 1}$, while at the outlet it is $\dot{\mathrm{m}}_{\mathrm{wc} 2}$ and $\mathrm{T}_{\mathrm{wc} 2}$. The mass flows of water at the inlet and outlet are the same $\dot{\mathrm{m}}_{\mathrm{wc} 1}=\dot{\mathrm{m}}_{\mathrm{wc} 2}$. The parameters of the medium in the cylinders are: mass $m_{S C}$, temperature $T_{S C}$ and pressure $p_{S C}$. The output parameters from the cylinders are the exhaust gas mass flow $\dot{\mathrm{m}}_{\mathrm{SC}}$, its temperature $\mathrm{T}_{\mathrm{SC}}$ and pressure $\mathrm{p}_{\mathrm{SC}}$. The medium with these parameters flow to the turbine of the turbocharger through the exhaust gas intake duct KDS. The parameters of the medium at the exhaust gas outlet from the duct KDS, being the output parameters to the turbine are: exhaust gas mass flow $\dot{\mathrm{m}}_{\mathrm{SP}}$, temperature $\mathrm{T}_{\mathrm{SP}}$ and pressure $\mathrm{p}_{\mathrm{SP}}$. The output parameters from the turbine are: torque $\mathrm{M}_{\mathrm{T}}$ and angular velocity of the rotor $\omega_{\mathrm{T}}$. Additionally, exhaust gas of the mass flow $\dot{\mathrm{m}}_{\mathrm{SP}}$, pressure $\mathrm{p}_{\mathrm{SP}}$ and temperature $\mathrm{T}_{\mathrm{SP}}$ flows out of the turbine. The medium from the turbine passes to the exhaust outlet channel KWS, from which it gets to the atmosphere. Additionally, in the case of a turbocharger, its torque and angular velocity have direct impact on the parameters of the air fed to the intercooler. Another group of output parameters in the cylinder section (piston rod-crankshaft) are the mechanical parameters such as crankshaft angular velocity $\omega$ and torque $\mathrm{M}_{\mathrm{WK}}$. These are the input parameters for the synchronous generator. The output parameters from the synchronous generator are interphase voltages as a function of crankshaft angle $\mathrm{U}_{1-2}$, $\mathrm{U}_{2-3}, \mathrm{U}_{3-1}$ and moment of resistance $\mathrm{M}_{\mathrm{OP}}$ being the input parameters for the cylinder sections of the engine. Additionally, in the model, the authors included the influence of the rotating components (mass of the crankshaft and the rotor of the synchronous generator). The reciprocating components have much less significant impact on the fluctuation of the crankshaft angular velocity. They were included in the OTSS engine module.

\subsection{Topological model}

Another type of model used in the analysis of the dynamics of a combustion engine is a topological model that includes the flow of the thermodynamic medium and the kinematic relations among the components of the engine design structure. This model is made by reproducing the functional model in a topological space $\tau$ o defined as $[2,3]$ :

$$
\tau o=(X, \Theta)
$$

where: $\mathrm{X}$ - finite set of vertexes including the elements of the design structure of the modeled object (in this case KDP, S, CH, REG, SC, AP, T, KWS, G, O) and the parameters describing its thermal flow properties (temperature, pressure, medium mass flow, engine speeds, efficiencies etc.). Additionally, it presents the mechanical parameters such as angular velocity, torque and resistance, $\Theta$ - topology determined in set $\mathrm{X}$ by overlaying binary relations in the topological space, understood as relations among the analyzed subcomponents and parameters of the condition of the thermodynamic medium as well as parameters of the structure of the subcomponents with particular stress on the energy efficiencies of the processes.

The functional properties of a real object make a finite set of pairs $(X, \Theta)$ of the topological space that can be presented in the form of a finite digraph $G(X, \Theta)$, i.e. elements of the set of vertexes $X=\left\{x_{i}\right\}$ combined with the elements of the set of relations $\Theta=\left\{\theta_{j}\right\}$. This graph shows which vertexes are mutually related as well as the type of those relations.

The construction of a topological model is performed in three fundamental stages [2]. The first stage includes a selection of the significant properties of the object functioning and reproducing them on a diagram through graph vertexes. The second stage consists in determining of the cause and effect relationship among the functional properties of the object that results from its principle of operation. In the third stage, a validation of the model and its potential supplementation is performed (determination of the detail level).

Based on the presented functional model (Fig. 2), a topological model was developed (Fig. 3). In this model, the authors distinguished the fundamental components of the engine design structure (red) and the efficiency of the processes occurring in flow machines (blue). Additional parameters of the engine processes were marked white. The figure presents the relation between the vertexes of the graph showing the analyzed components of the design structure of the engine-generator set. The diagram of the mutual relations was supplemented with mass flows of the thermodynamic medium. They can be determined based on other parameters describing the energy state of an engine:

- The mass flow of air fed to the engine is constant for the compressor, intercooler and the combustion chambers: $\dot{\mathrm{m}}_{\mathrm{DOL}}=\dot{\mathrm{m}}_{\mathrm{CHt}}=\dot{\mathrm{m}}_{\mathrm{CYL}}$. Its value can be expressed as a function of volume of the combustion chamber $\mathrm{V}_{\mathrm{CYL}}$, cylinder volume efficiency $\eta_{\mathrm{V}}$, air density $\rho_{\mathrm{CYL}}$, engine speed $\mathrm{n}$ and number of engine strokes $\mathrm{s}$.

$$
\dot{\mathrm{m}}_{\mathrm{DOL}}=\mathrm{V}_{\mathrm{SC}} \cdot \eta_{\mathrm{V}} \cdot \rho_{\mathrm{CYL}} \cdot \frac{\mathrm{n}}{\mathrm{s}}
$$

- The fuel mass flow $\dot{m}_{\mathrm{PAL}}$ is a function of engine speed regulator $r$, position of the fuel rail l, engine speed $n$ and charging pressure $\mathrm{p}_{\mathrm{CYL}}$.

$$
\dot{\mathrm{m}}_{\mathrm{PAL}}=\mathrm{f}\left(\mathrm{r}, \mathrm{l}, \mathrm{n}, \mathrm{p}_{\mathrm{CYL}}\right)
$$

- The exhaust gas mass flow is constant for the combustion chamber and the exhaust gas outlet. It is described by the relation: $\dot{\mathrm{m}}_{\mathrm{SP}}=\dot{\mathrm{m}}_{\mathrm{KWS}}$. Its value is a sum of the value of the air mass flow $\dot{\mathrm{m}}_{\mathrm{CYL}}$ and the fuel mass flow $\dot{\mathrm{m}}_{\mathrm{PAL}}$.

$$
\dot{\mathrm{m}}_{\mathrm{SP}}=\dot{\mathrm{m}}_{\mathrm{KWS}}=\dot{\mathrm{m}}_{\mathrm{CYL}}+\dot{\mathrm{m}}_{\mathrm{PAL}}
$$

The presented topological model of the marine generator composed of a diesel engine and a synchronous generator allows determining mutual relations among individual components of the assembly. In this model, analogically to the functional model, the input parameters are: temperature $\mathrm{T}_{0}$, pressure $\mathrm{p}_{0}$, individual gas constant $\mathrm{R}_{0}$ and intake air humidity $\varphi_{0}$. The air feeding the engine goes to the intake duct KDP where its pressure drops $\Delta \mathrm{p}_{\mathrm{KDP}}$. From the duct, 
the air goes to the compressor, at the outlet of which it has the parameters: $\dot{\mathrm{m}}_{\mathrm{CH}}, \mathrm{p}_{\mathrm{CH}}$ and $\mathrm{T}_{\mathrm{CH}}$. The compressor has the compression rate $\pi$ and efficiency $\eta_{\mathrm{es}}$. Similarly to the functional model, the heat exchange in the intercooler $\mathrm{CH}$ was allowed for along with the pressure drop in the intercooler $\Delta \mathrm{p}_{\mathrm{CH}}$. The air from the intercooler goes to the engine cylinders SC. The cylinders are also fed with fuel mass flow $\dot{\mathrm{m}}_{\mathrm{PAL}}$ that depends on the engine speed regulator setting $\mathrm{R}+\mathrm{PP}$ and the fuel system AP. The air mass flow feeding the cylinders $\dot{\mathrm{m}}_{\mathrm{CYL}}$ and the mass fuel flow $\dot{\mathrm{m}}_{\mathrm{PAL}}$ determine the excess air coefficient $\lambda$. The function of the excess air coefficient is the engine speed $\omega$ and the amount of heat released following the process of combustion. Knowing the material properties and the thickness of the cylinder liners, cylinder heads and piston crowns, it is possible to determine the amount of released heat to the water that cools the cylinders. From the cylinder section, flows the exhaust gas of the mass flow of $\dot{\mathrm{m}}_{\mathrm{SC}}$ and parameters such as: temperature $\mathrm{T}_{\mathrm{SC}}$ and pressure $\mathrm{p}_{\mathrm{SC}}$. The exhaust gas feeds the turbine of the turbocharger $\mathrm{T}$ through the exhaust inlet duct. In the turbine, the energy of the exhaust gas is converted into torque $\mathrm{M}_{\mathrm{T}}$ and rotor speed $\omega_{\mathrm{T}}$. After leaving the turbine, the exhaust has the mass flow $\dot{\mathrm{m}}_{\mathrm{KWS}}$, temperature $\mathrm{T}_{\mathrm{KWS}}$ and pressure $\mathrm{p}_{\mathrm{KWS}}$. Then it goes to the exhaust gas outlet duct KWS, for which the flow resistance $\Delta \mathrm{p}_{\mathrm{KWS}}$ was allowed for. The exhaust gas from the outlet (KWS) goes to the atmosphere. As a result of the conversion of chemical energy into heat inside the cylinders, the gas force is generated whose consequence is the torque $M_{W K}$ and the crankshaft angular velocity $\omega_{\mathrm{WK}}$. Both the torque and the engine speed are the output parameters from the cylinder section. These are the input parameters for the syn- chronous generator. Additionally, the engine speed is the input parameter for the engine speed regulator. The output parameters of the generator are the value of the interphase voltages $\mathrm{U}_{1-2}, \mathrm{U}_{2-3}, \mathrm{U}_{3-1}$ and the value of the current for each of the engine phase $\mathrm{I}_{1}, \mathrm{I}_{2}, \mathrm{I}_{3}$.

\subsection{Physical model}

Based on the performed logical analysis of the design structure, a physical model was developed. It generally characterizes the mutual relations between the analyzed components of the design structure of the research object. Depending on the designation, such a model can be developed as zero-, one- or multi-dimensional [7, 8]. In simple applications, usually zero-dimensional models are used, where the only independent parameter is time and the outstanding parameters are its functions. Adopting a zerodimensional model greatly simplifies the mathematical equations describing the said relations. Another type of models is a one-dimensional model, in which the independent variables are time and one geometrical dimension. Such an approach to modeling complicates the mathematical relations but allows analyzing the processes occurring, for example, during the flow of a fluid through a channel. One-dimensional models are often used during the analysis of the wave phenomena in the flow channels of combustion engines [6]. Higher groups of models allow a multidimensional (two or three) determination of the flow of a medium allowing for such phenomena as turbulence. Due to their complexity and a great number of calculations, these models are very time consuming and solving them is a great challenge even for contemporary computers (great amount of time and computing power) [8].

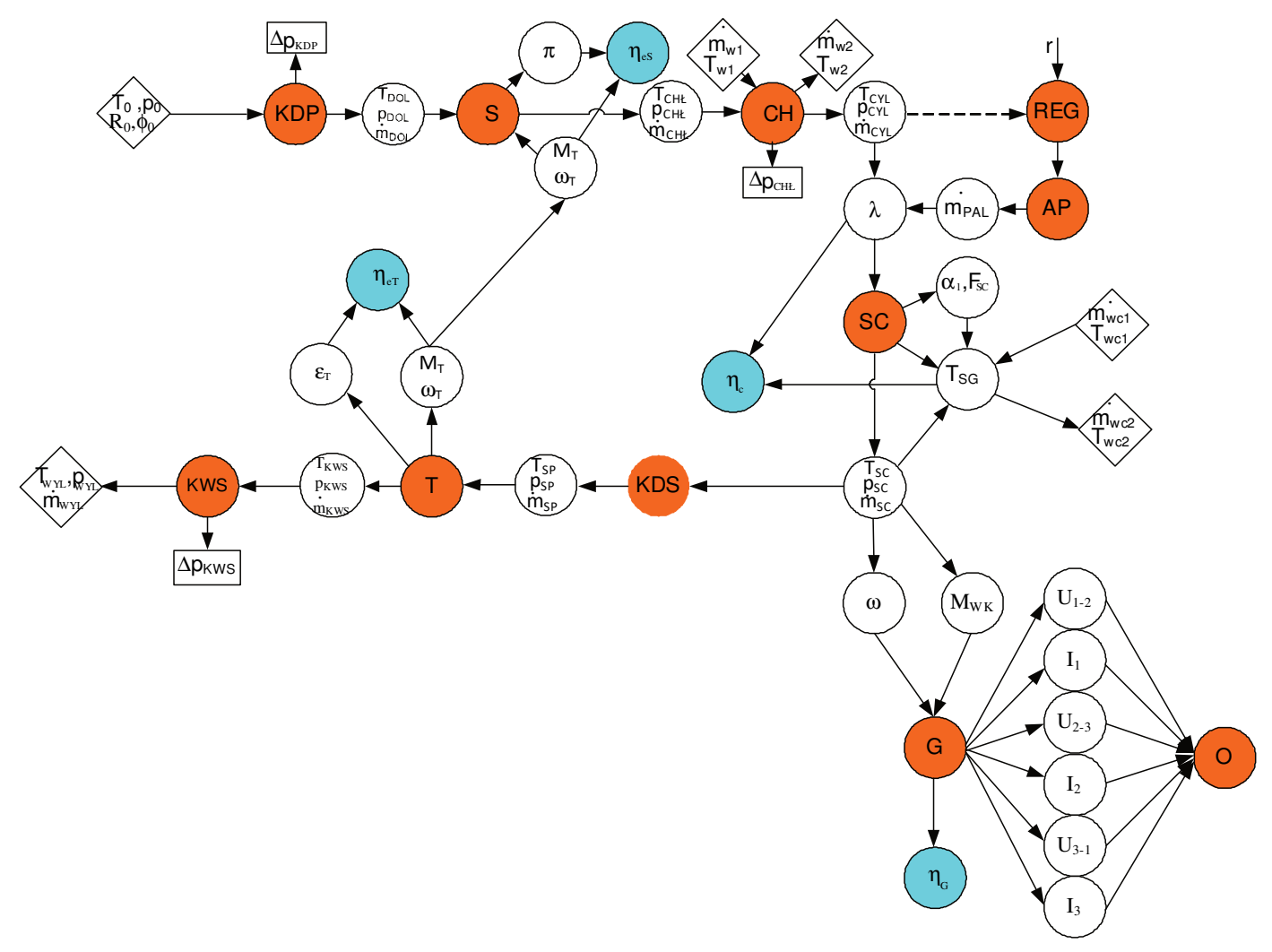

Fig. 3. Topological model of the marine generator set 
A physical model of thermodynamic and mechanical processes constitutes a foundation for the development of the mathematical model containing balance equations that allow determining the parameters (both thermodynamic and mechanical) selected in the physical model. Balance equations contained in the model can be solved with computer software, which is often referred to as the simulation or numerical model. In practice, the software only allows a quick solution of the equations included in the mathematical model.

In the conducted research, it was assumed that the developed models must allow introducing modifications to the engine technical condition. It will allow using them in the widely understood diagnostics. The introduction of the modification to the engine technical condition allows simulating known and identifiable malfunctions that may occur in a real object.

In the adopted physical model the input parameters are:

- dimensions of the crankshaft-piston assembly,

- intake and exhaust valve lifts as a function of crankshaft angle $h_{\text {ZAW }}=f(\alpha)$,

- dimensions of the intake and exhaust valve poppet and valve face,

- injector opening angle $\alpha_{\mathrm{PAL}}$,
- moment of resistance applied to the engine being the consequence of the load from the generator $\mathrm{U}, \mathrm{I}=\mathrm{f}(\alpha)$ (allows calculating the fuel mass injected into the cylinder during a work cycle),

- cylinder intake air pressure $\mathrm{p}_{\mathrm{CYL}}=\mathrm{f}(\alpha)$,

- fuel calorific value $W_{P A L}$,

- fuel temperature $\mathrm{T}_{\mathrm{PAL}}$,

- cylinder cooling water temperature $\mathrm{T}_{\mathrm{wc} 1}$,

- heat conductance parameters of materials used for the pistons, cylinder liners and cylinder head,

- thickness of the piston crown, cylinder liner and cylinder head,

- moment of inertia of the rotating and reciprocating masses.

The output parameters are:

- pressure curves inside the engine cylinders $p_{C Y L}=f(\alpha)$

- temperature curves inside the engine cylinders $\mathrm{T}_{\mathrm{CYL}}=$ $f(\alpha)$

- engine speed curves as a function of crankshaft angle $\omega=\mathrm{f}(\alpha)$,

- curves of the interphase voltage as a function of crankshaft angle $\mathrm{U}_{1-\mathrm{L} 2}, \mathrm{U}_{2-\mathrm{L} 3}, \mathrm{U}_{3-\mathrm{L} 1}=\mathrm{f}(\alpha)$.

The proposed physical model has been presented in Fig. $4[10,11]$.

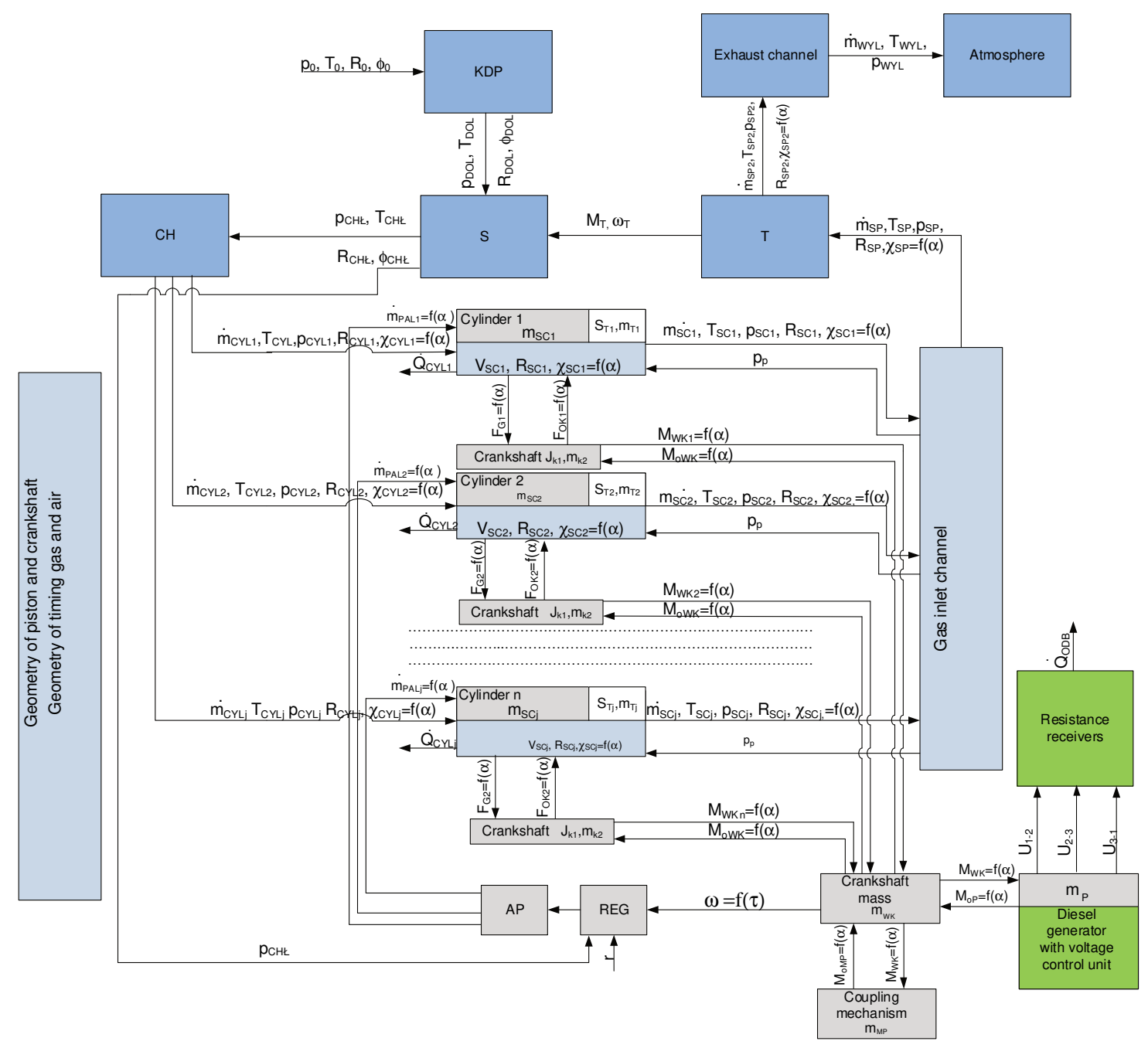

Fig. 4. Physical model of the marine generator set 
The physical model of the marine generator set was developed in order to ensure high universality, i.e. to allow modeling of processes occurring practically in any marine engine powering a generator. In order to ensure the universality of the model, the following assumptions were adopted:

- the model applies to a four stroke diesel engine,

- the number of cylinders is $1-8$,

- it is possible to freely modify the cylinder firing order,

- the engine is turbocharged, if not turbocharged, the intake air parameters feeding the cylinders $\mathrm{p}_{\mathrm{CYL}}, \mathrm{T}_{\mathrm{CYL}}$, $\dot{\mathrm{m}}_{\mathrm{CYL}}, \chi_{\mathrm{CYL}}$ correspond to the parameters of ambient air $\mathrm{p}_{0}, \mathrm{~T}_{0}, \dot{\mathrm{m}}_{0}, \chi_{0}$,

- it is possible to modify the injection angle,

- it is possible to modify the timing system parameters (intake and exhaust valve opening and closing angles, valve lifts and their dimensions),

- it is possible to modify all dimensions related to the piston-crankshaft assembly, valve poppet and valve face.

All components of the model are zero-dimensional, i.e. the independent variable is time. The first model component is the air intake duct, from which the input parameters are the parameters of ambient air. From the intake channel the air goes to the compressor, at the outlet of which it has parameters: $\mathrm{p}_{\mathrm{CH}}, \mathrm{T}_{\mathrm{CH}}, \mathrm{R}_{\mathrm{CH}}$ and $\chi_{\mathrm{CH}}$. In the case of an unsupercharged engine, it is assumed that the parameters are $\mathrm{p}_{\mathrm{CH}}=\mathrm{p}_{0}=\mathrm{p}_{\mathrm{CYL}}, \mathrm{T}_{\mathrm{CH}}=\mathrm{T}_{0}=\mathrm{T}_{\mathrm{CYL}}, \mathrm{R}_{\mathrm{CH}}=\mathrm{R}_{0}=$ $\mathrm{R}_{\mathrm{CYL}}$ and $\chi_{\mathrm{CH}}=\chi_{0}$. Obviously, the individual gas constant for air depends on its processing, hence $\mathrm{R}_{0}=\mathrm{R}_{\mathrm{DOL}}=$ $\mathrm{R}_{\mathrm{CHE}}=\mathrm{R}_{\mathrm{CYL} 1}=\mathrm{R}_{\mathrm{CYL} 2}=\cdots=\mathrm{R}_{\mathrm{CYLj}}$. The air flowing out of the compressor goes to the intercooler, at the outlet of which it has parameters: $\mathrm{p}_{\mathrm{CYL}}, \mathrm{T}_{\mathrm{CYL}}, \mathrm{R}_{\mathrm{CYL}}$ and $\chi_{\mathrm{CYL}}$. Other components are the engine cylinders that can accumulate mass of the thermodynamic medium, which is denoted by mass $\mathrm{m}_{\mathrm{SC}}$. Significant input parameters of the cylinders (except those already mentioned) are the fuel $\dot{\mathrm{m}}_{\mathrm{PAL}}$ and air $\dot{\mathrm{m}}_{\mathrm{CYL}}$ mass flows. The air mass flow is a function of charging pressure, air temperature, its humidity, intake valve opening and closing angle and cylinder capacity $\dot{\mathrm{m}}_{\mathrm{CYL}}=$ $f\left(p_{C Y L}, T_{C Y L}, \rho_{C Y L}, V_{C Y L}, \alpha_{O Z D}, \alpha_{Z Z D}\right)$. The fuel mass flow $\dot{\mathrm{m}}_{\mathrm{PAL}}$ directly depends on the setting of the engine speed regulator REG, the engine speed $\omega$ and the charging pressure $\mathrm{p}_{\mathrm{CH}}$. Another group of input parameters are the dimensions of the piston-crankshaft assembly, intake and exhaust valves opening and closing angles as well as the injection advance angle. When modeling the cylinder sections of the engine, the masses of the piston, the pivot and the attributed part of the connecting rod were taken into account (marked as $\mathrm{m}_{\mathrm{T}}$ ). These are reciprocating masses. Rotating masses were also included in the model (crankshaft with an attributed part of the connecting rod, clutch, generator rotor). In order to calculate the pressure of the gasses, it was necessary to calculate the surface area of the piston crown $\mathrm{S}_{\mathrm{T}}$. The gas-dynamic output parameters from the cylinders being at the same time the input parameters to the outlet duct are the exhaust gas pressures $\mathrm{p}_{\mathrm{SP}}$ and temperatures $\mathrm{T}_{\mathrm{SP}}$, exhaust gas mass flows $\dot{\mathrm{m}}_{\mathrm{SP}}$ and the isentropic exponents $\chi_{\mathrm{SP}}$. Additionally, the authors included in the model the impact of the pressure counteracting the outflow of gasses from the cylinders $p_{P}$ and the dynamic of the reciprocating and rotating components. To this end, the authors considered the distributions of mass of selected components of the engine design structure. This was particularly the case for the piston and the pivot performing the reciprocating motion, the connecting rod performing a combined reciprocating and rotating motion and the crankshaft performing the rotating motion. The combined motion of the connecting rod was considered as reciprocating motion of a mass determined with the weight system of the head of the connecting rod with the attributed mass, while the rotating motion pertained to the foot of the connecting rod with the outstanding mass [9]. When building the model, forces generated as a result of the exhaust gas pressure on the piston crown $\mathrm{F}_{\mathrm{SC}}$ as well as forces acting on the piston through the connecting rod $\mathrm{F}_{\mathrm{OK}}$ were allowed for. Also, the inertia forces of the piston-connecting rod assembly $\mathrm{I}_{\mathrm{K}}$ were allowed for in the model. In the model, it was assumed that all masses and moments of inertia of the suspended mechanisms are treated globally and are attributed to the mass and moment of inertia of the crankshaft.

The torque from the crankshaft is transferred to the rotor of the generator $\mathrm{M}_{\mathrm{WK}}$. The generator acts on the engine with its moment of resistance $\mathrm{M}_{\mathrm{OP}}$. When modeling the generator, the authors assumed that the only rotating mass is the mass of the rotor $m_{P}$. The generator, being a synchronous device, generates alternating three-phase voltage of the frequency of $50 \mathrm{~Hz}$ (corresponding to the double frequency resulting from the engine crankshaft revolution). Majority of generators used in the marine sector has two pairs of poles for each of the phases. Loading the generator with current receivers results in a flow of current of the voltage $\mathrm{U}_{\mathrm{L}}$ and intensity $\mathrm{I}_{\mathrm{L}}$. Due to the fact that receivers have resistance, the power collected from the generator can be expressed as a product of voltage and current. The consumption of power from the generator is a source of load for the engine with the moment of resistance $\mathrm{M}_{\mathrm{OP}}$.

\section{Conclusions}

The physical model of the processes occurring in the marine generator set presented in the paper constitutes a basis for the development of a mathematical model of energetic processes of a diesel engine powering a synchronous generator. Further research is related to the development of mathematical models of a diesel engine, the assessment of its adequacy based on the comparison of the model and the experimental results as well as the design and assessment of the adequacy of the mathematical model of the engine-generator assembly.

\section{Nomenclature}

m mass

M torque $\dot{m}$ mass flow

$\mathrm{n} \quad$ engine speed 


\begin{tabular}{llll}
\hline $\mathrm{Nr}$ & engine speed setting & $\mathrm{U}$ & voltage \\
$\mathrm{p}$ & pressure & $\chi$ & polytropic exponent \\
$\mathrm{R}$ & individual gas constant & $\omega$ & angular velocity \\
$\mathrm{T}$ & temperature & to & topological space
\end{tabular}

\section{Abbreviations and indexes}

0 applies to parameters of the atmosphere

1-2 applies to the voltage between phases 1 and 2

2-3 applies to the voltage between phases 2 and 3

3-1 applies to the voltage between phases 3 and 1

CHE intercooler, applies to the air at the inlet to the intercooler

CYL applies to the parameters of air fed to the cylinders

DOL applies to the intake parameters

KDP intake duct

KDS exhaust intake to the turbine

KWS exhaust outlet

OP, OP1, OP2 applies to the moment of resistance of the receiver

OTSS marine piston combustion engine

PAL applies to fuel

REG engine speed regulator
Sp applies to the parameters of exhaust fed to the turbine of the turbocharger

$\mathrm{Sp} 2$ applies to the exhaust gas flowing out of the turbine of the turbocharger

SC applies to the parameters of the medium inside the cylinders and at their outlet

SPR compressor

$\mathrm{T}$ turbine

w1 applies to the parameters of water at the inlet to the intercooler

w2 applies to the parameters of water at the outlet to the intercooler

wc1 applies to the parameters of water fed to cool the cylinders

wc2 applies to the parameters of water extracted after cooling the cylinders

\section{Bibliography}

[1] CANNON, R.H. Dynamika uktadów fizycznych. WNT. Warszawa, 1973.

[2] HEBDA, M., MAZUR, T., PELC, H. Teoria eksploatacji pojazdów. WKE. Warszawa, 1978.

[3] HEBDA, M., NIZIŃSKI, S., PELC, H. Podstawy diagnostyki pojazdów mechanicznych. WKE. Warszawa, 1980.

[4] KORCZEWSKI, Z., ZACHAREWICZ, M. Diagnostyka symulacyjna układu turbodoładowania okrętowego tłokowego silnika spalinowego. Zeszyty Naukowe AMW. 2007, 2(169), 73-102.

[5] KORCZEWSKI, Z., ZACHAREWICZ, M. Introduction to diagnostics investigation of marine diesel engines at limited monitoring susceptibility. Journal of POLISH CIMAC. 2008, 3(2), 65-74.

[6] KORCZEWSKI, Z., ZACHAREWICZ, M. Metoda diagnozowania silników okrętów wojennych o ograniczonej możliwości pomiaru ciśnień wewnątrzcylindrowych na podstawie wyników badania procesów gazodynamicznych w ukła-

Tomasz Kniaziewicz, DSc., DEng. - Faculty of Mechanical and Electrical Engineering, Polish Naval Academy, Gdynia.

e-mail:T.Kniaziewicz@amw.gdynia.pl dzie turbodoładowania. Gdynia, AMW, Projekt badawczy 0T00B02129, 2008.

[7] MAŃCZAK, K. Planowanie eksperymentu. WNT. Warszawa 1976.

[8] SOBIESZCZAŃSKI, M. Modelowanie procesów zasilania w silnikach spalinowych. WKE. Warszawa 2000.

[9] SZCZECIŃSKI, S. Lotnicze silniki tłokowe. MON. Warszawa 1969.

[10] ZACHAREWICZ, M., CWALINA, A. Research on energetic processes in a marine diesel engine driving a synchronous generator for diagnostic purposes Part 1 - Physical model of the processes. Journal of POLISH CIMAC. PG, 2013, 8(1).

[11] ZACHAREWICZ, M., KNIAZIEWICZ, T., BOGDANOWICZ, A. Physical model of energetic processes in the marine diesel engine. Zeszyty Naukowe AMW. 2017, 4(211), 512.

[12] Międzynarodowa konwencja o bezpieczeństwie życia na morzu, 1979 SOLAS, Tekst ujednolicony. Gdańsk, Polski Rejestr Statków, 2002.

Marcin Zacharewicz, DEng. - Faculty of Mechanical and Electrical Engineering, Polish Naval Academy, Gdynia.

e-mail:M.Zacharewicz@amw.gdynia.pl 